\title{
INVESTIGATION OF ADVANCED COMPONENTS IN A HIGH PRESSURE SINGLE- CELL ELECTROLYSER FOR THE DEVELOPMENT OF A HP-PEM-ELY STACK AS PART OF A REGENERATIVE FUEL CELL SYSTEM
}

\author{
Dimitrios K. Niakolas ${ }^{(1)}$, Stylianos Neophytides ${ }^{(1)}$, Constantinos G. Vayenas ${ }^{(2)}$, Alexandros Katsaounis $^{(2)}$, \\ Nikolaos Athanasopoulos ${ }^{(3)}$, Stella Balomenou ${ }^{(4)}$, Kalliopi-Maria Papazisi ${ }^{(4)}$, Dimitrios Tsiplakides ${ }^{(4)}$, \\ Max Schautz (5) \\ (1) Foundation for Research and Technology, Hellas (FORTH), Greece, Email: niakolas@iceht.forth.gr \\ (2) Department of Chemical Engineering, University of Patras, Greece, Email: cgvayenas@upatras.gr \\ (3) Advent Technologies SA, Greece, Email: nikos.athanasop@gmail.com \\ (4) Centre for Research and Technology - Hellas (CERTH), Greece, Email: stellab@cperi.certh.gr \\ ${ }^{(5)}$ European Space Research and Technology Centre (ESTEC), The Netherlands, Email: max.schautz@esa.int
}

\begin{abstract}
The objective of the presented work, done under current ESA activity (Contract No. $4000109578 / 13 / \mathrm{NL} / \mathrm{SC})$, is the performance and tolerance evaluation of selected components and materials for the development of a High Pressure, Polymer Electrolyte Membrane (PEM) Electrolyser (HP-PEM-ELY) Stack, aiming to operate at 80 bar with a performance output of $0.3 \mathrm{~A} / \mathrm{cm}^{2}$ at $1.6 \mathrm{~V}$. An extensive study was performed on a single-cell high pressure PEM electrolyser manifold, leading to a list of materials with suitable properties and engineering solutions towards operation in space environment. This investigation provided the necessary feedback for the design of a HP-PEM-ELY stack, which is also discussed. The ultimate target of the current ESA activity is to implement research findings, develop and operate a complete regenerative fuel cell system, comprising of a High Temperature Fuel Cell Stack and the HP-PEM-ELY stack. System aspects are briefly discussed.
\end{abstract}

\section{INTRODUCTION}

Regenerative fuel cells offer significant advantages over rechargeable batteries as energy storage devices, especially in applications where high specific energy density is required as in the case of telecommunication satellites. A closed loop regenerative PEM fuel cell system (RPEMFCS) operates as a high pressure PEM electrolyser when excess power is available from the solar array (charging mode/reactant regeneration) and as a PEM fuel cell when the solar array does not generate power i.e. when the satellite is in eclipse (discharge mode). It has to be mentioned that operation of an electrolyser at high pressure is advantageous due to (i) reduction of internal cell resistance, (ii) reduction of volume of gas bubbles, which facilitates the transportation of liquid water and (iii) production of compressed $\mathrm{H}_{2}$ and $\mathrm{O}_{2}$, which makes the electrolyser to perform at the same time as a gas compressor.
Regenerative fuel cells, of a discrete or a unitized design. have been considered as potential energy storage solution for future space missions [1]. The ultimate objective of the current ESA activity is the research and development of a regenerative PEM fuel cell (RPEMFC) system for space applications, targeting at (a) large telecommunication platforms in geostationary orbit, GEO (Commercial application) and (b) planetary exploration missions (Science application). Based on the materials research and development, which has been carried out up to now, two stacks (a high-pressure PEM electrolyser and a high-temperature PEM fuel cell) are under manufacturing and preliminary testing, aiming to be incorporated in a regenerative fuel cell test bench for further evaluation [2]. Complete testing of the system will be performed under a predefined load profile corresponding to the needs of a telecom platform in GEO orbit.

\section{MATERIALS TESTING AND ELECTROCHEMICAL MEASUREMENTS ON A SINGLE HP-PEM-ELY}

The single-cell HP-PEM-ELY experiments employed commercial, low temperature, $5 \times 5 \mathrm{~cm}^{2}$ reinforced Catalyst Coated Membranes (CCMs - FumaTech) with Pt-based (cathode) and IrOx-based (anode) electrodes. It has to be mentioned that several materials have been examined as materials or components, including various types of current collectors, sealing materials, bipolar plates and CCMs of various thicknesses. Furthermore, a complete study on efficient and stable Ir-based electrocatalysts for the Oxygen Evolution Reaction (OER), which has been performed under the current and previous ESA activities (Contracts 21113/07/NL/LvH and $22329 / 09 / \mathrm{NL} / \mathrm{CBI})$ is behind the targeted development. In this study, the results mainly deal with those components that have been finally selected to be applied in the development of the stack including: (i) properly treated Titanium plates as $\mathrm{O}_{2}$ current collector, (ii) carbon paper GDL (Freudenberg) as $\mathrm{H}_{2}$ current collector, (iii) sealing materials based on FKM200 
(Freudenberg), PTFE, etc. and (iv) properly treated Titanium film for the cathode $\left(\mathrm{H}_{2}\right)$ side bipolar plate.

Fig. 1 shows the single-cell HP-PEM-ELY manifold, operated in a lab-bench top facility with pressure equilibration for anode and cathode chambers, so that all measurements there performed under no differential pressure. The selected $\mathrm{O}_{2}$ current collector is placed inside a carbon bipolar plate.

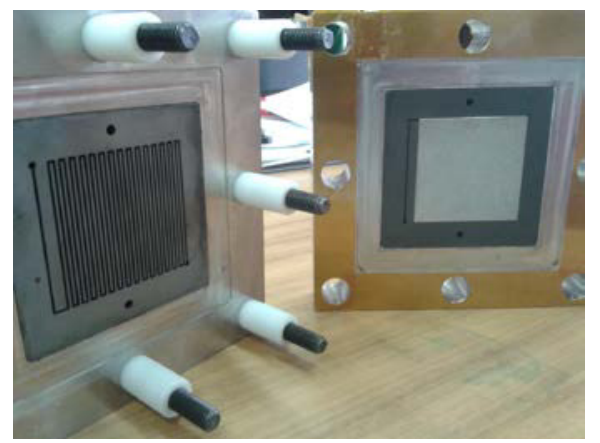

Figure 1. Single-cell High Pressure ELY reactor.

The first noteworthy remark from the single cell measurements came out by using under preliminary tests carbon paper (with GDL) as current collector in both electrodes. During the electrochemical measurements, depicted in Fig. 2, there was a continuous degradation of the anode $\left(\mathrm{O}_{2}\right)$ current collector, accompanied with the observation of a blackcolored outlet feed from the $\mathrm{O}_{2}$ side. The degradation of the $\mathrm{O}_{2}$ current collector is attributed to the oxidation of carbon by the evolved $\mathrm{O}_{2}$, towards the formation of $\mathrm{CO}_{2}$, which further induces the mechanical disintegration of the current collector. Moreover, it explains, up to a certain extent, the fact that by increasing the operating pressure, apart from the overpotential increase in the ohmic region of the I-V curves, there seems to be a shift of the slope in the activation overpotential region.

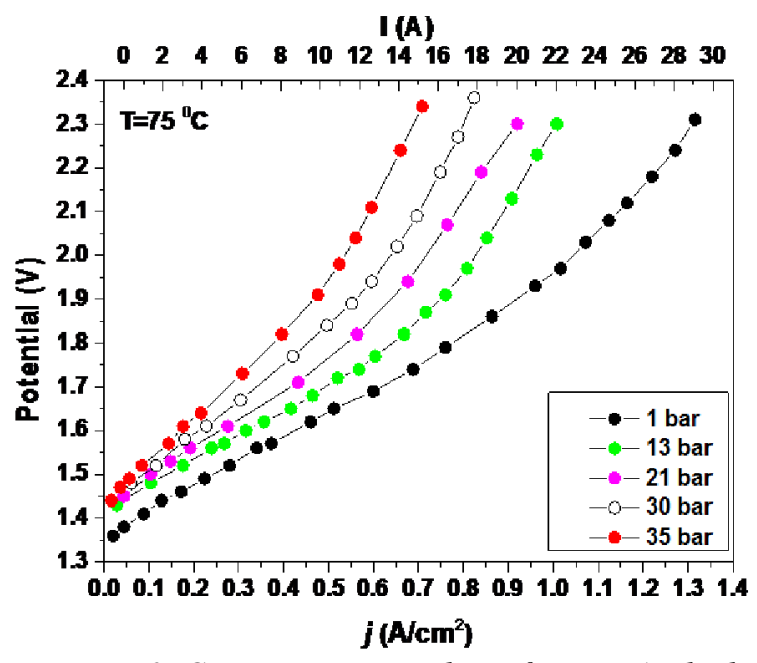

Figure 2. Comparative I-V plots of an MEA which comprises carbon paper as $\mathrm{O}_{2}$ and $\mathrm{H}_{2}$ current collector.
In terms of performance, the results in Fig. 2 show that above 13 bar of operating pressure the specific membrane electrode assembly (MEA) cannot reach the desired performance, $\left(0.3 \mathrm{~A} / \mathrm{cm}^{2}\right.$ at $\left.1.6 \mathrm{~V}\right)$, and this is primarily attributed to the degradation of the $\mathrm{O}_{2}$ current collector, whereas the thickness of the membrane $(250 \mu \mathrm{m})$ is as additional factor.

The best performing MEAs under high pressure resulted by applying a combination of: (i) new type of sealing materials (e.g. PTFE and other), (ii) properly treated porous Titanium plate as $\mathrm{O}_{2}$ current collector and (iii) carbon paper as $\mathrm{H}_{2}$ current collector. Fig. 3 shows the comparison in performance of two different MEAs at $\mathrm{P}=1$ bar and $\mathrm{T}=73{ }^{\circ} \mathrm{C}$. Their main difference lies on the fact that one MEA has carbon paper as $\mathrm{H}_{2}$ current collector, while the other comprises carbon paper and properly treated Ti foil. The thickness of both MEAs is approximately $150 \mu \mathrm{m}$ and the sealing has been made through a combination of PTFE gaskets. Moreover, both MEAs have been assembled in such a way, so that they have the same thickness overall.

I-V plots in Fig. 3 show that both MEAs have similar performance and it is obvious that the presence of treated Ti foil on the $\mathrm{H}_{2}$ side does not have a negative effect. On the contrary, it seems that it facilitates the overall performance, especially at high current densities. This is most probably attributed to the fact that it ensures better contact of the carbon paper with the electrode and facilitates the current collection. Thus, treated $\mathrm{Ti}$ foil as an additional current collector on the $\mathrm{H}_{2}$ side seems as a promising solution for the HP-PEMELY stack.

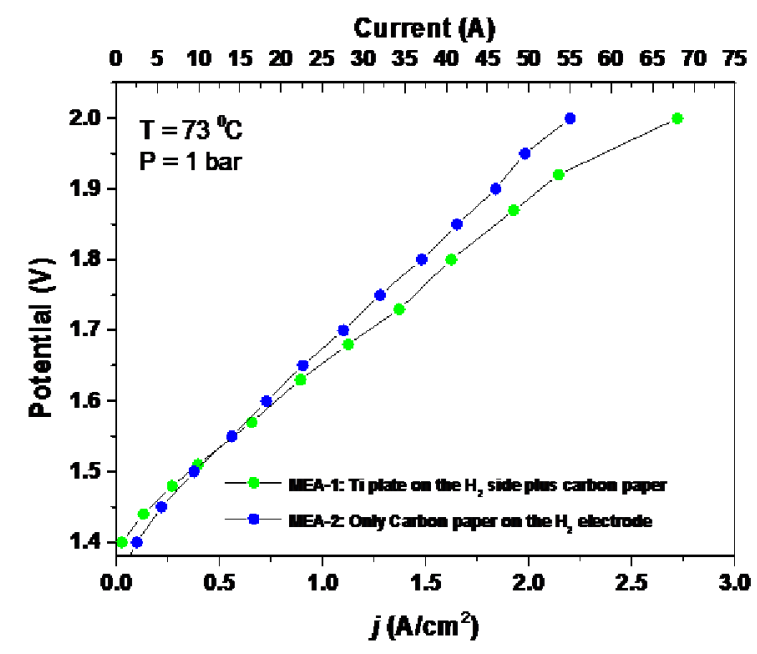

Figure 3. I-V curves of two different MEAs that comprise treated sintered Ti plate as $\mathrm{O}_{2}$ current collector. MEA-1 comprises carbon paper and treated Ti foil as $\mathrm{H}_{2}$ current collector, while MEA-2 has only carbon paper with GDL.

The same MEA-1 in Fig. 3, with the treated Ti foil on the $\mathrm{H}_{2}$ side, was also examined under high pressure. In addition, it was left inactive for approximately 1 month 
in order to find out whether it would need a second reactivation stage or if the $1^{\text {st }}$ activation process, which always takes place prior its operation, is sufficient. Fig. 4 shows the performance before and after one (1) month of idleness, including the operation at high pressure.

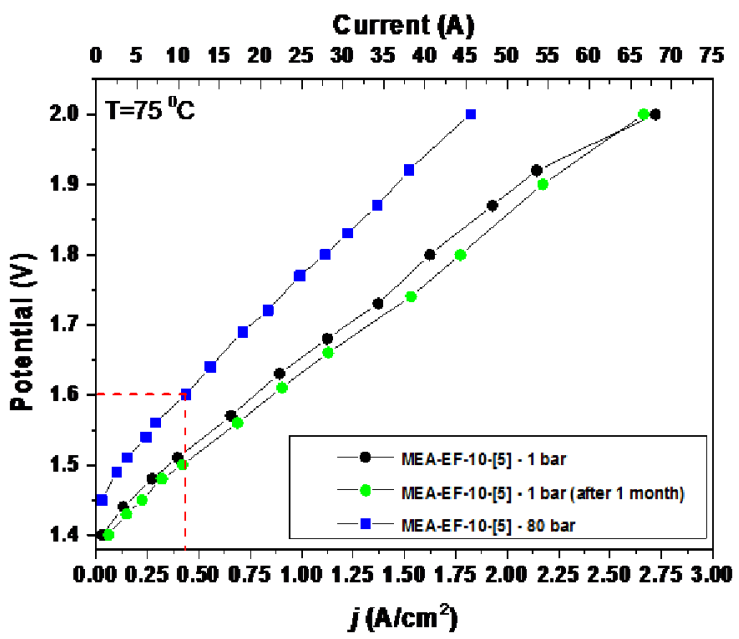

Figure 4. I-V curves of MEA-1, which comprises treated sintered Ti plate as $\mathrm{O}_{2}$ current collector and treated Ti

foil plus carbon paper as $\mathrm{H}_{2}$ current collectors.

The first interesting remark from Fig. 4 , is that the $1^{\text {st }}$ activation step is enough and despite the fact that the electrolyzer was idle for approximately one month this did not affect its performance, which was quite similar at $\mathrm{P}=1$ bar and $\mathrm{T}=75{ }^{\circ} \mathrm{C}$. The second important remark is that it managed to operate on a stable basis at $\mathrm{P}=80$ bar with a current density of $0.44 \mathrm{~A} / \mathrm{cm}^{2}$ at $1.6 \mathrm{~V}$, which is higher than the required $\left(0.30 \mathrm{~A} / \mathrm{cm}^{2}\right.$ at $\left.1.6 \mathrm{~V}\right)$, yielding thus an efficiency of $89 \%$. Moreover, the whole I-V plot shows low overpotential at 80 bar. Specifically, there is a rational increase of the Open Circuit Potential, due to the high operating pressure value ( 80 bar), but the activation, ohmic and concentration overpotentials have not significantly increased. There seems to be a degradation, which can be attributed to ohmic losses that could be related to gradual loosening of the reactor at $\mathrm{P}=80$ bar, which however did not result in important gas leakage.

The above thorough measurements have provided necessary feedback and a selected list of materials/components and solutions for the design and manufacture of the HP-PEM-ELY stack.

\section{DESIGN OF THE HIGH PRESSURE ELECTROLYSER STACK}

A preliminary design of the High Pressure Electrolyser (HP-PEM-ELY) stack is presented in the following, Figs. 5 and 6 . It has to be stressed that the maximum pressure of 80 bar does not allow the use of large area MEAs, due to the high developed axial and bending forces at the bolts and the end plates. Gaskets, O-rings and bipolar plates should withstand hydrogen embrittlement effects at temperatures up to $82^{\circ} \mathrm{C}$. Regarding structural parts, the most significant properties are high specific strength and stiffness. In particular, materials and geometry of the various peripheral parts were studied thoroughly before being selected. The most suitable materials have been identified in order to fulfil the main design objectives for the following parts:

- End plates (Cell structured Aluminium)

- Force regulators and base (Aluminium \& Stainless steel)

- Bolts (Aluminium)

- Piping system (Aluminium)

- Gaskets (PTFE-type)

- Springs (high strength SS)

- Treated Ti plates current collector $\left(\mathrm{O}_{2}\right.$ side $)$

- Carbon paper with GDL current collector $\left(\mathrm{H}_{2}\right.$ side)

- Treated Ti foil bipolar plates

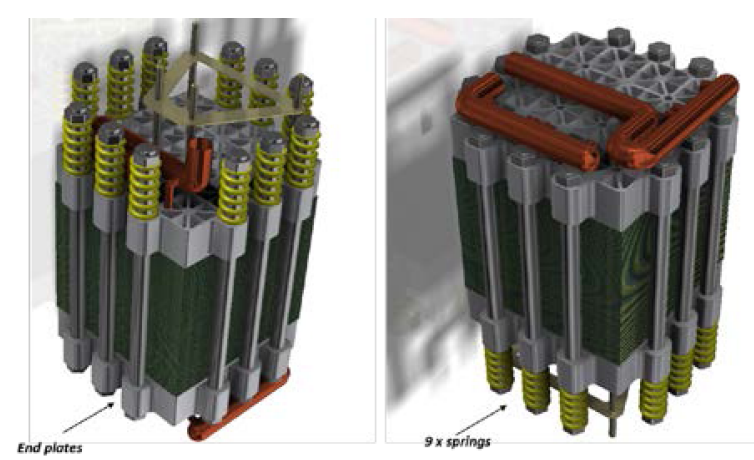

Figure 5. Two different iso-views of the design for HPPEM-ELY stack and the various parts.
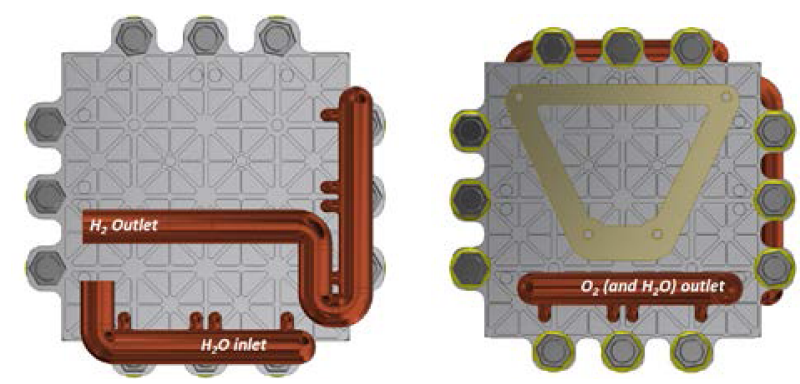

Figure 6. Plan views of the end-plates of the design for HP-PEM-ELY stack

\section{DESIGN OF THE REGENERATIVE FUEL CELL SYSTEM}

The complete regenerative fuel cell system, comprising of a High Temperature Fuel Cell Stack and the HPPEM-ELY stack, will be based on the existing R-PEMFC test bench at the premises of CERTH, developed and operated under previous projects on REGENERATIVE PEM FUEL CELLS (Contracts 21113/07/NL/LvH and 22329/09/NL/CBI). Besides the 
test items (PEM fuel cell and electrolyzer stacks), the reactants' storage and feed subsystems, the thermal management system and the electronic peripherals, functional and performance requirements have been defined and described in detail. The main requirements of the regenerative PEM fuel cell system are:

- Continuous Operation. The system will operate in a continuous cycle between power production and reactant regeneration. Following a specific test load profile, the system will operate under fuel cell (FC) mode in order to provide constant power and consecutively in electrolyser (ELY) mode for complete regeneration of the reactants.

- Closed loop operation. Reactants (hydrogen and oxygen) produced during electrolyser (ELY) mode are used for power generation during fuel cell (FC) mode. Water produced during FC mode shall be circulated to produce the reactants during ELY mode.

The requirements of the pressurised $\mathrm{H}_{2}$ and $\mathrm{O}_{2}$ gas handling/storage system need careful selection of materials and safety specifications to be used. In order to meet these requirements, custom-made products are employed or developed, ensuring proper and safe operation in the long term testing period. The sizing of the gas tanks was based on the stoichiometry of water splitting reaction $\left(\mathrm{H}_{2} / \mathrm{O}_{2}: 2 / 1\right)$; therefore, in order to have a balanced electrolyser pressure (no pressure difference between anode and cathode compartments) the $\mathrm{H}_{2}$ tank has double the volume of the $\mathrm{O}_{2}$ tank. The power provisions for the system are at the level of $5 \mathrm{~kW}$ for the fuel cell stack and $3 \mathrm{~kW}$ for the electrolyzer stack.

Based on these requirements, and more specifically, reactants storage at elevated pressure (70-100 bar) and avoidance of moving parts (e.g. compressors, pumps), the complete closed loop system has been designed and is under realization (refurbishment of existing infrastructure).

Regarding test planning. the system shall be cycled in a profile representative for a GEO telecommunication satellite, in a 1-year accelerated test profile representative of 15 years of field operation, covering both eclipse seasons $(2 \times 45$ eclipses per year with a duration of $4.9 \mathrm{~min}$ to $72 \mathrm{~min}$ ) as well as the sunlight season (need for electric propulsion (thrust) for orbit correction once per week).

\section{CONCLUSIONS AND FUTURE WORK}

The key remarks and future planning for development under current ESA activity on regenerative PEM fuel cells (4000109578/13/NL/SC), are summarized here:

- High pressure single-cell measurements operated on a stable basis up to $\mathrm{P}=80$ bar at $\mathrm{T}=75^{\circ} \mathrm{C}$ with a performance above the desired threshold of $j=0.3 \mathrm{~A} / \mathrm{cm}^{2}$ at $\mathrm{V}=1.6 \mathrm{~V}$.

- There is low but gradual decrease of the current density by increasing the operating pressure.
- The treated Ti plate on the $\mathrm{O}_{2}$ side is an effective current collector under high pressure conditions.

- The treated $\mathrm{Ti}$ foil on the $\mathrm{H}_{2}$ side in combination with carbon paper as current collector, seem as proper bipolar and current collecting materials, under high pressure conditions.

- A combination of PTFE-type gaskets as sealing materials, shows to be effective for stable operation at high pressure values ( 80 bar).

- The so far obtained results from the single-cell HPPEM-ELY setup have provided the necessary feedback on the proper materials and components for the design of a $1.5 \mathrm{~kW}$ light-weight HP-PEMELY stack, which is currently under development.

- Upon completion of the closed loop regenerative system (refurbishment of existing infrastructure) preliminary tests for qualifying the functionality of the system and test items (FC and ELY stacks) will commence.

\section{REFERENCES}

1. ESA Electrochemical Energy Storage Roadmap, 2011.

2. Executive Summary Report from activity GTF2065: "Regenerative PEM Fuel Cells" (ESA Contract 22329/09/NL/CBI) 